\title{
Aportes de lA SEDIMENTOLOGÍA A LOS ESTUdios GEOARQUEOLÓGICOS Y PALEOAMBIENTALES: SECUENCIAS ESTRATIGRÁFICAS EN AMBIENTES VOLCÁNICOS EN LA REGIÓN Cauca Medio, Colombia
}

\author{
Carlos Eduardo López ${ }^{a}$, Martha Cecilia Cano ${ }^{b}$ y Jorge Andrés Vargasc
}

\begin{abstract}
Resumen
Este articulo sintetiza los enfoques investigativos que el LEHPC viene aportando a los estudios geoarqueológicos hacia la recuperación, registro y análisis de sedimentos, buscando información secuencial que señale variabilidad, la cual puede ser correlacionada temporal y culturalmente. Se presenta el método seguido para obtener algunos resultados cuantitativos a partir de la separación de los componentes gruesos y finos de los suelos en secuencias intrasitio. Las aproximaciones desde la sedimentología como proxy, aportan datos complementarios para superar los alcances de las solas descripciones visuales o las limitantes de costos de análisis especializados en muchos niveles estratigráficos. La colección de materiales obtenida brinda datos para explicar la formación y dinámica de los suelos, al establecer relaciones con las distintas ocupaciones humanas, particularmente en ambientes volcánicos. Se viene consolidando una "sedimentoteca", la que se convierte en un referente de consulta y espacio fisico de almacenaje apropiado, para investigaciones sobre las secuencias estratigráficas.
\end{abstract}

Palabras clave: tefraestratigrafía, abanico fluvio-volcánico, secuencia histórico-cultural, sedimentoteca

\section{Abstract \\ SEDIMENTOLOGICAL APPROACHES TO GEOARCHAEOLOGICAL AND PALEOENVIRONMENTAL STUDIES: STRATIGRAPHIC SEQUENCES IN VOLCANIC ENVIRONMENTS IN THE CAUCA MEDIO REGION, COLOMBLA}

When reviewing soil and sediment aspects in some publications and archaeological reports -as well as when consulting archives and materials stored in Archaeology laboratories-it is common to find incomplete or non-basic related information. This article points to the need to strengthen training and practice related to the complexity of stratigraphic aspects, both in their descriptions and analysis in the field, and in the laboratory. In this direction, for nearly a decade LEHPC has been strengthening geoarcheological studies and particularly the recovery, recording, and sedimentological analysis in relation to the paleoenvironmental and archaeological interests. We present the results of applying a simple and economical process to obtain sequential information that provides variability to be interpreted temporally and culturally. Up to 54 sites stratigraphic studies show the presence of pre-Hispanic evidence from pre-Ceramic times in the Middle Cauca (central western Colombia), and depositional dynamics of the volcanic environment of the Cerro Bravo-Cerro Machin complex are related, on the western slope of the Cordillera Central. The method is based on obtaining quantitative data from the separation on coarse-and-fine components from soils andlor sediments into intra-site sequences. Approaches from sedimentology appear as a proxy, providing complementary data for the geoarcheological studies; it incorporates quantitative data into the paleoenvironmental interpretation in interdisciplinary perspective. This analytical technique supports the scopes of the single visual descriptions or the limitations of costs of physical-chemical characterization

a https://orcid.org/0000-0001-9757-2475 _Laboratorio de Ecología Histórica y Patrimonio Cultural (LEHPC), Universidad Tecnológica de Pereira (Colombia).cel@utp.edu.co

b https://orcid.org/0000-0002-3140-5807 Laboratorio de Ecología Histórica y Patrimonio Cultural (LEHPC, Universidad Tecnológica de Pereira (Colombia). mcano@utp.edu.co

c https://orcid.org/0000-0002-1073-3166 Laboratorio de Ecología Histórica y Patrimonio Cultural (LEHPC), Universidad Tecnológica de Pereira (Colombia). jorge.vargas@utp.edu.co 
analysis when applied to many stratigraphic levels. The collection obtained provides material data to establish aspects of soil formation and dynamics at the regional level, as well as to determine the relationships between soils and sediments of sites linked to different human occupations, showing in particular the characteristics of volcanic deposits. The "sedimentoteca" under construction becomes a reference of consultation and physical storage space, for future research into stratigraphic sequences.

Keywords: tephrastratigraphy, fluvio-volcanic fan, sediments collection, cultural historic sequences

\section{Introducción}

Desde el Laboratorio de Ecología Histórica y Patrimonio Cultural (LEHPC) de la Universidad Tecnológica de Pereira (UTP) se han venido desarrollando investigaciones sobre las relaciones entre naturaleza-cultura en perspectiva geoarqueológica, particularmente en ambientes volcánicos. En la cuenca media del río Cauca — en la zona centro-occidental de Colombia — se han reportado secuencias deposicionales que permiten relacionar evidencias materiales prehispánicas de épocas cerámicas y precerámicas, las cuales indican la permanencia cultural de larga duración en zonas próximas al complejo volcánico Cerro Bravo-Cerro Machín (Aceituno y Loaiza 2007; Restrepo 2012; Cano et al. 2013, 2015; Herrera et al. 2016; Posada 2017) (Fig. 1).

Considerando las condiciones particulares que generan los volcanes activos en el segmento norte de la Cordillera Central colombiana se planteó la importancia de levantar columnas estratigráficas de suelos superficiales desarrollados sobre cenizas jóvenes. Esta tarea se ha adelantado en medio centenar de sitios — a diferentes alturas — buscando aportar al conocimiento de la historia volcánica del Holoceno (desde aproximadamente 11,700 años cal AP) y sus implicaciones sobre el poblamiento humano de la macrorregión (Cano et al. 2013, 2015; Cano 2018). Además, se ha buscado fortalecer la discusión de resultados de otros estudios que han sumado a la perspectiva geoarqueológica y paleoambiental en la región del Cauca Medio, como los de Aceituno y Loaiza (2007) y Posada (2017).

Se ha logrado describir la variabilidad estratigráfica a partir de sistematizar procesos de análisis sedimentológicos, generando un modelo replicable al usar la sedimentología como proxy. El mayor interés de este ejercicio ha sido acercar a los arqueólogos a realizar análisis de laboratorio — sencillos y de bajo costo- en los que se tenga un contacto directo con los suelos y se logren correlacionar resultados que muestran variaciones estratigráficas intra e inter sitio ${ }^{1}$. Los ambientes deposicionales volcánicos se prestan para establecer correlaciones lito y pedoestratigráficas, teniendo en cuenta la distancia a los focos eruptivos y las elevaciones, aportando al relacionar aspectos cronológicos y culturales con mejor integridad.

Se ha venido enfatizando el acercamiento geoarqueológico como marco teórico y metodológico interdisciplinar de interés — en el que la sedimentología como uno de sus componentes_ aporta en la valoración de los componentes fisiográficos y estratigráficos (Waters 1992; Rapp y Hill 1998; Favier-Dubois 2010). Nos surgen preguntas asociadas sobre las dinámicas de las causas y consecuencias de la formación y transformación de los sitios arqueológicos, los paisajes y las dinámicas paleoambientales, proyectando consideraciones cronológicas y culturales a escalas local y regional.

\section{Problemática de investigación}

Aunque la relación de los arqueólogos es permanente con la matriz de suelos y sedimentos, en muchos casos - particularmente en Colombia — hace falta formación especializada en esta dimensión. Se presentan debilidades en las descripciones de campo, así como en las decisiones metodo- 


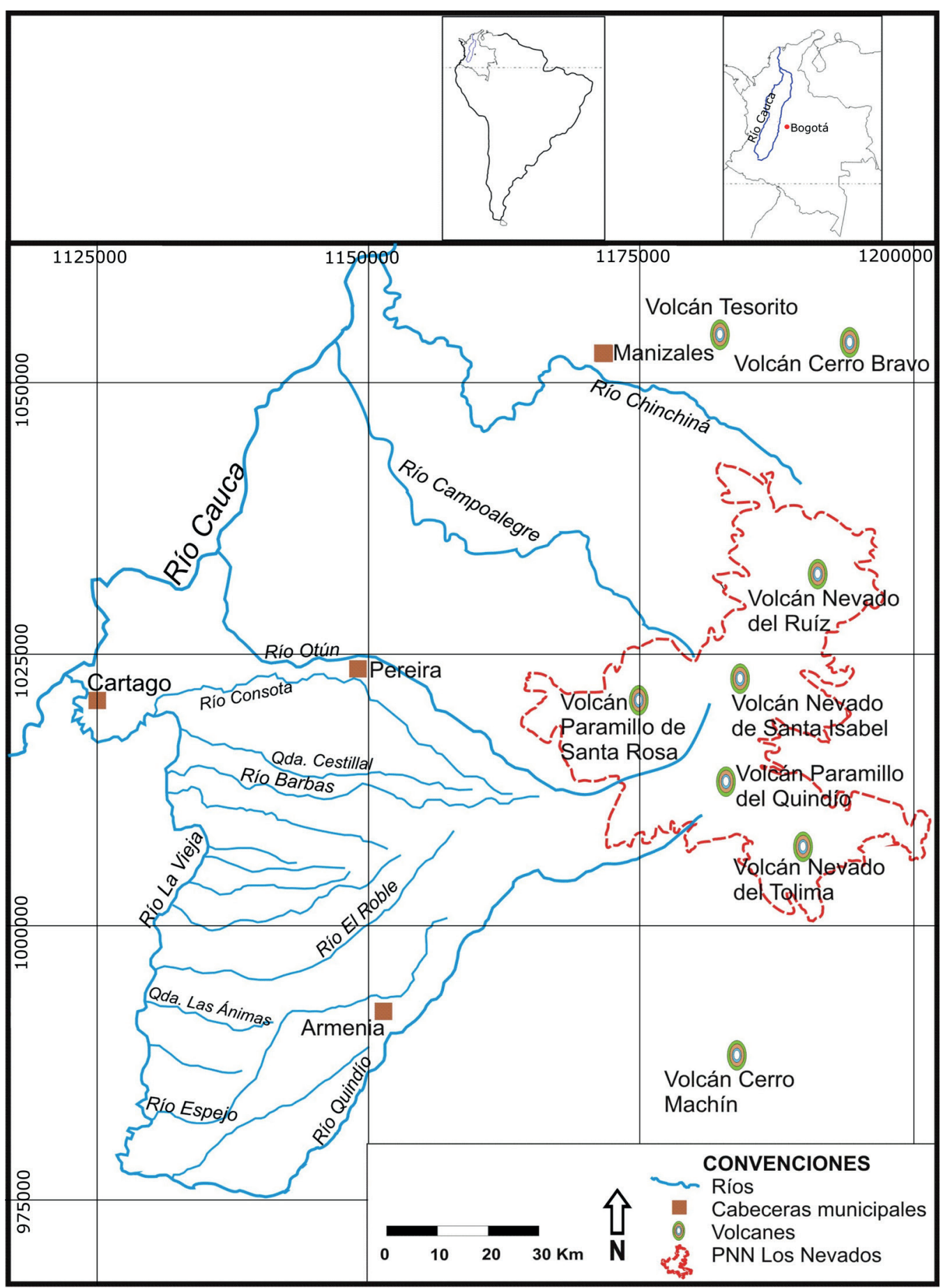

Figura 1. Localización del sector estudiado en la región del Cauca Medio. Se destaca la red hidrica que enmarca el contexto del abanico fluvio-volcánico Pereira-Armenia. Al oriente se destaca el macizo volcánico Cerro Bravo-Cerro Machin (figura de Martha Cecilia Cano, 2018). 
lógicas sobre cuales datos colectar y cómo mejorar el ejercicio. Una falencia es que se parte de una formación generalista de pregrado que apenas incluye algunas clases ${ }^{2}$ sobre ciencias de la tierra. En la mayoría de los casos son los mismos arqueólogos - con mínima formación en el ámbito de la geoarqueología - que han construido su experiencia personal con suelos o sedimentos, en ocasiones guiados por especialistas en Ciencias de la Tierra (Botero 2001).

Otras debilidades asociadas en los informes, muestran descripciones muy generales de sondeos o cortes, con fotos apenas visibles — con sombras en los perfiles_-, además con determinaciones poco claras de las variaciones estratigráficas. Se suelen presentar mecánicamente los cambios de colores y texturas, pero falta profundizar sobre sus dinámicas de formación y cambio. Cuando los recursos lo permiten algunas muestras son enviadas para caracterización físico-química, pero sus resultados suelen aparecer como anexos, sin aprovechar al máximo el potencial de su información. Falta un contacto más directo de los arqueólogos con los suelos y los sedimentos donde aparece el registro cultural. Inquieta además el manejo y descarte de estos materiales, sin posibilidades de uso hacia futuras consultas. A menudo se almacenan temporalmente pesadas bolsas, recuperadas para análisis y flotación, pero desafortunadamente hacen parte del primer grupo de materiales que se descarta.

Ante esta problemática y nuestros intereses de investigación en perspectiva ambiental, desarrollamos ejercicios prácticos y sencillos de sedimentología, buscando establecer un protocolo sistemático. Así se diseñó una base de datos con los resultados y se viene montando una colección física de referencia de los productos ya separados y tamizados.

\section{Metodología de análisis de sedimentos en laboratorio}

Se viene replicando un proceso para la separación de componentes del suelo, logrando asignar valores de referencia cuantitativos. Aunque existen métodos de laboratorio como el denominado de «la pipeta» que separan fracciones limo y arcilla (Murcia et al. 2008), en este caso no consideramos aplicarlo, teniendo en cuenta los intereses de nuestras preguntas y el procesamiento directo que proponemos a escala básica, sin necesidad de utilizar equipos costosos de laboratorio o químicos dispersantes (como hexametafosfato de sodio u otros) (Méndez 2004; Murcia et al. 2008). En la Figura 2 se sintetiza el proceso ${ }^{3}$ seguido para separar los componentes gruesos y finos, así como su posterior tamizaje $e^{4} y$ almacenamiento final (LEHPC 2016, LEHPC 2017; López et al. 2016; Cano 2018) (Fig. 2 a Fig. 5).

Como lo han planteado varios autores, una de las principales características físicas de los depósitos vulcanoclásticos es el tamaño de las partículas que lo constituyen, por lo que para su descripción son utilizadas varias escalas que discriminan entre los tamańos ${ }^{5}$. Se debe tener en cuenta que la distribución del tamaño de grano varía de un depósito a otro, por tanto, el procedimiento para el análisis textural depende no solo de la precisión requerida, sino también del rango de tamaño de partículas disponibles (Méndez 2004; Murcia et al. 2008).

Una vez registrados los datos en hojas electrónicas y tablas, se pasa a la etapa de análisis donde de manera gráfica se pueden observar cambios, los cuales indican variaciones en las tendencias, relacionados con la composición mineral y el peso de los componentes depositados. Adicionalmente se pueden obtener distintos histogramas, elaborar curvas de distribución y conseguir curvas de frecuencia acumulada para todas las muestras colectadas. Para este estudio no se hicieron determinaciones detalladas de los tamaños aún más finos de limos y arcillas; aunque se reconoce como una posibilidad de interpretaciones por ejemplo de cambios paleoclimáticos y paleoambientales (Aceituno y Loaiza 2007; Posada 2017), ya que nuestra investigación se focalizó en otra dimensión. 


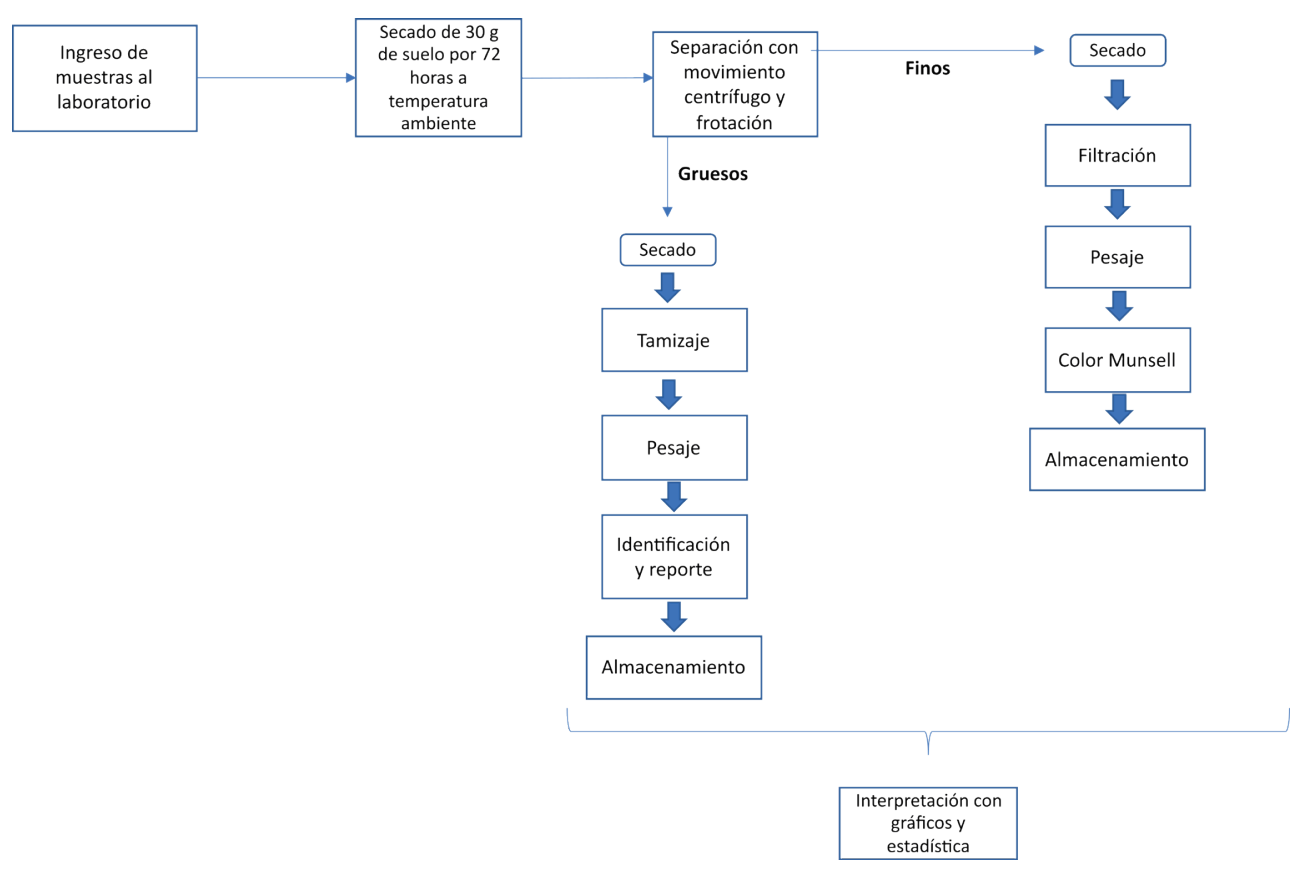

Figura 2. Diagrama de flujo del proceso sedimentológico (figura de Jorge Andrés Vargas, 2020).

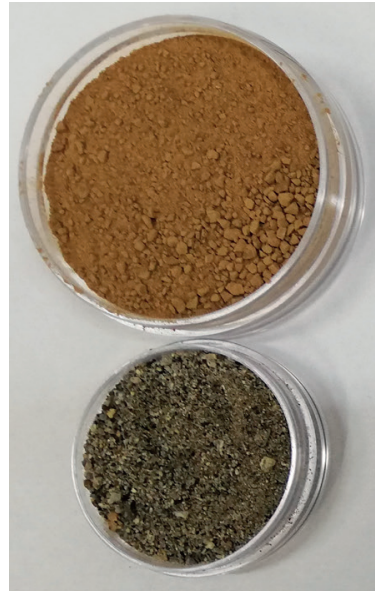

Urbanización Bella Suiza Manizales Etapa 7 Corte 2 $80 \mathrm{~cm}$ prof.

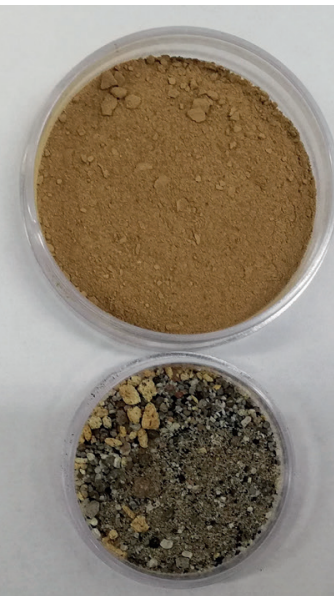

Urbanización Bella Suiza Manizales Etapa 7 Corte 2 $130 \mathrm{~cm}$ prof.

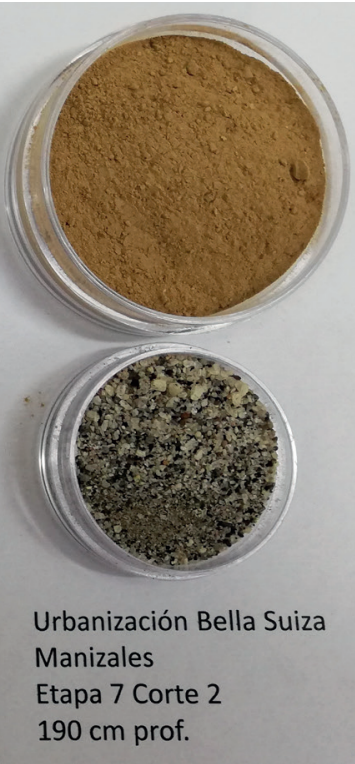

Figura 3. Resultados de la separación entre componentes finos (que guardan el color) y gruesos. Se trata de tres niveles de profundidad distintos (figura de Carlos Eduardo López, 2020). 

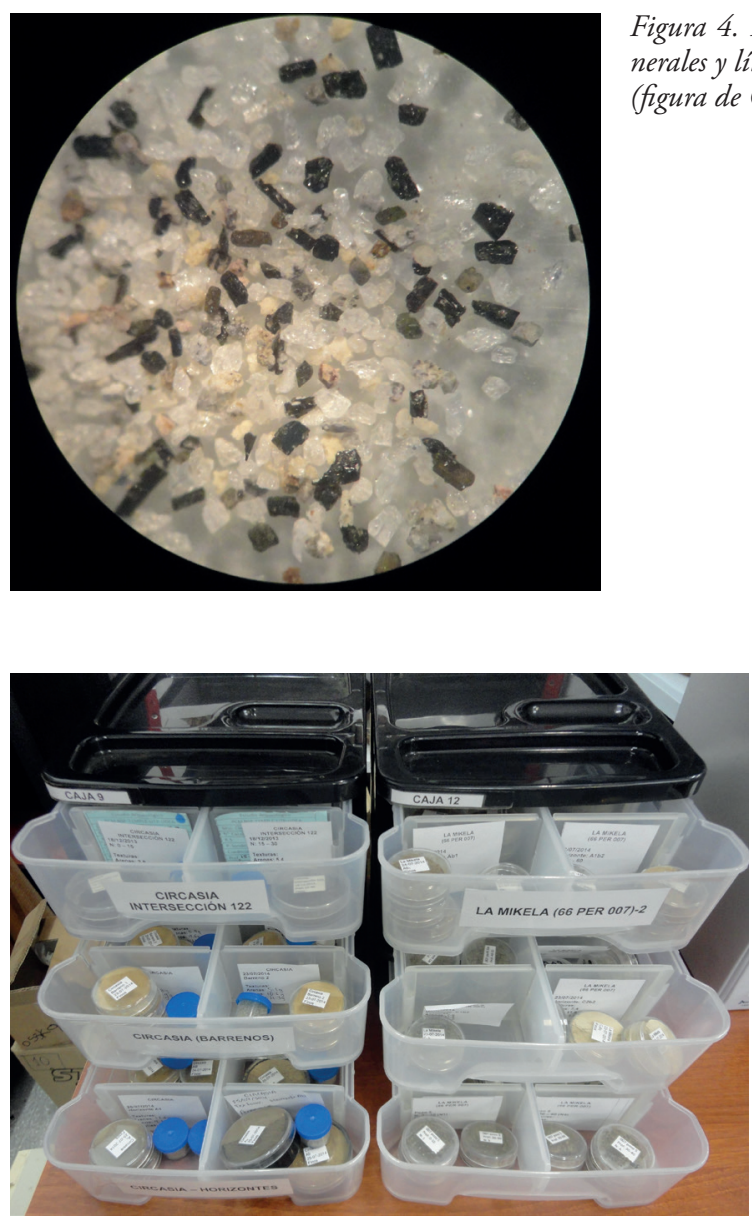

Figura 4. Detalle en la lupa binocular de los sedimentos minerales y líticos en una muestra de productos gruesos analizada (figura de Carlos Eduardo López, 2020).
Figura 5. Recipientes y cajones para almacenar los sedimentos que facilitan su preservación (figura de Carlos Eduardo López, 2020).

\section{Avances en correlaciones intra e inter sitios}

Además de la consideración de la altura sobre el nivel del mar — las cuales se relacionan con la distancia relativa a los focos volcánicos, así como indican diferenciación de las dinámicas de meteorización-, se tomó como una de las variables de referencia, el peso porcentual de los sedimentos gruesos, referenciado por niveles de profundidad. Así fue posible conocer cuáles sitios se destacaron por sobrepasar ciertos rangos, lo cual pudo ser relacionado con depósitos que revelaban mayor representatividad y preservación de los materiales de origen volcánico. A partir de las tendencias de los resultados del conjunto de datos obtenidos se determinó un marcador relativo para cotejar información en ambientes volcánicos a escala regional, tomando como referencia los valores superiores o iguales al $45 \%$ de peso de materiales gruesos. Se consideró la rigurosidad establecida en los procedimientos de laboratorio, los cuales establecen límites porcentuales máximos de error (20\% para finos y 10\% para gruesos) entre resultados de una muestra y su duplicado (LEHPC 2016, LEHPC 2017).

El proceso de tamizaje aportó datos complementarios, pues siendo el material de mayor tamaño, los fenocristales ${ }^{6}$ y líticos retenidos en los tamices 40 y 60, se presentan como indicadores de depósitos relacionados con dinámicas vulcanoclásticas de significativa magnitud, además de brindar la información granulométrica sobre tipo de componentes y posibles orígenes. Las dinámicas de evolución edafológica indicaron en algunos casos que algunos paquetes de cenizas 

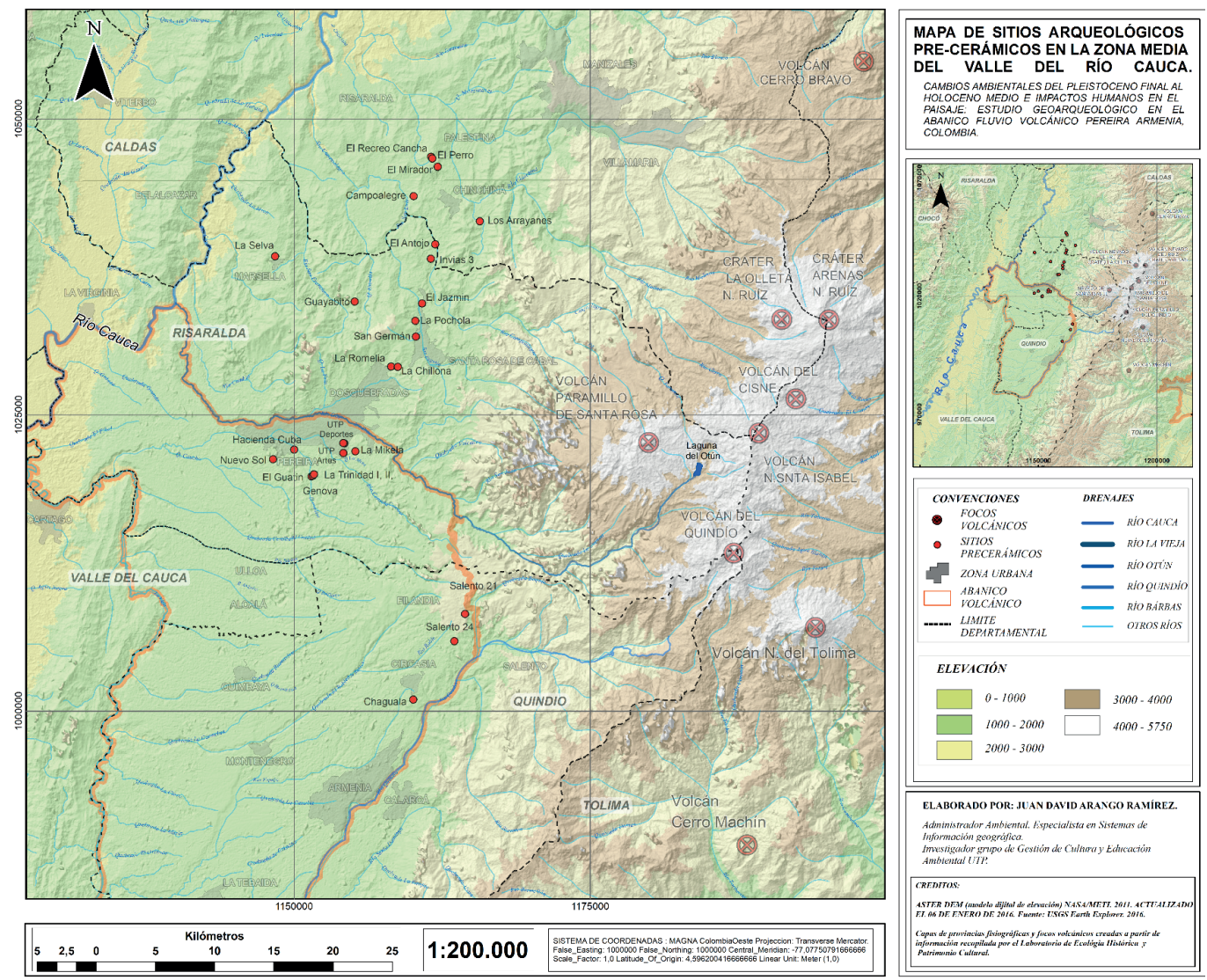

Figura 6. Zona de estudio en la vertiente occidental de la Cordillera Central. Ubicación de los sitios muestreados, la mayoría dentro del Abanico Pereira-Armenia (figura de Juan David Arango, 2017).

fueron rápidamente sedimentados por nuevos eventos. Los sedimentos referenciados y su variación pueden ser interrelacionados en muchos sitios del Cauca Medio con las evidencias arqueológicas presentes en la matriz de suelo que los contiene.

\section{5. Área de estudio y contextualización de algunos resultados}

Se definió como área de estudio un polígono en la vertiente occidental de la Cordillera Central con un área aproximada de 400 kilómetros cuadrados, en la macrorregión conocida como Cauca Medio (Fig. 6). Se diseńaron recorridos por distintas carreteras y caminos buscando observar cortes donde se hiciera visible la estratigrafía y particularmente la presencia de capas de arenas gruesas, suelos enterrados o algún tipo de evidencia arqueológica superficial o subsuperficial. Así se logró documentar una serie de sitios arqueológicos situados en distintas unidades geomorfológicas dentro del abanico fluvio-volcánico Pereira Armenia. Se localizaron nuevos sitios y se revisitaron los excavados previamente por el LEHPC y por otros colegas (Tabla 1) (López et al. 2016; Cano 2018).

El abanico fluvio-volcánico Pereira-Armenia aparece como área de especial interés geológico y geomorfológico ${ }^{7}$ (Toro y Hermelin 1991; Guarín et al. 2004; Lalinde y Toro 2004; Tistl 2006; 


\begin{tabular}{|l|c|l|c|}
\hline \multicolumn{1}{|c|}{ Unidad geomorfológica } & $\begin{array}{c}\text { Rango alti- } \\
\text { tudinal }\end{array}$ & \multicolumn{1}{|c|}{ Características climáticas } & $\begin{array}{c}\text { \# de sitios } \\
\text { muestreados }\end{array}$ \\
\hline $\begin{array}{l}\text { Colinas bajas y relieve suavemente } \\
\text { ondulado de la Cordillera Central }\end{array}$ & $1800-2000$ & $\begin{array}{l}18-22^{\circ} \mathrm{C}, 2600 \mathrm{~mm} \text { anual, } 86 \% \text { humedad } \\
\text { relativa, } 1280 \text { hora/año brillo solar }\end{array}$ & 5 \\
\hline $\begin{array}{l}\text { Relieve moderado con incisión de } \\
\text { drenajes sector medial del Abanico }\end{array}$ & $1300-1600$ & $\begin{array}{l}18-22^{\circ} \mathrm{C}, 2200 \mathrm{~mm} \text { anual, } 86 \% \text { humedad } \\
\text { relativa, } 1280 \text { hora/año brillo solar }\end{array}$ & 5 \\
\hline $\begin{array}{l}\text { Relieve plano y suavemente ondu- } \\
\text { lado del sector distal del Abanico }\end{array}$ & $1000-1200$ & $\begin{array}{l}18-24^{\circ} \mathrm{C}, 1900 \mathrm{~mm} \text { anual, } 80 \% \text { humedad } \\
\text { relativa, } 1825 \text { hora/año brillo solar }\end{array}$ & 6 \\
\hline $\begin{array}{l}\text { Basamento Terciario y frente de ero- } \\
\text { sión río La Vieja }\end{array}$ & $900-1100$ & $\begin{array}{l}18-24^{\circ} \mathrm{C}, 1900 \mathrm{~mm} \text { anual, } 80 \% \text { humedad } \\
\text { relativa, } 1825 \text { hora/año brillo solar }\end{array}$ & 4 \\
\hline $\begin{array}{l}\text { Colinas alargadas entre los ríos } \\
\text { Consota y Cestillal }\end{array}$ & $1200-1400$ & $\begin{array}{l}18-22^{\circ} \mathrm{C}, 2600 \mathrm{~mm} \text { anual, } 86 \% \text { humedad } \\
\text { relativa, } 1280 \text { hora/año brillo solar }\end{array}$ & 6 \\
\hline Altos topográficos & 1600 & $\begin{array}{l}18-22^{\circ} \mathrm{C}, 2600 \mathrm{~mm} \text { anual, } 86 \% \text { humedad } \\
\text { relativa, } 1280 \text { hora/año brillo solar }\end{array}$ & 3 \\
\hline Relieve plano a levemente ondulado & $1200-1300$ & $\begin{array}{l}18-24^{\circ} \mathrm{C}, 1900 \mathrm{~mm} \text { anual, } 80 \% \text { humedad } \\
\text { relativa, } 1825 \text { hora/año brillo solar }\end{array}$ & 1 \\
\hline $\begin{array}{l}\text { Colinas tipo media naranja en las } \\
\text { partes bajas entre los ríos Consota y } \\
\text { Otún }\end{array}$ & $1200-1500$ & $\begin{array}{l}18-22^{\circ} \mathrm{C}, 2600 \mathrm{~mm} \text { anual, } 86 \% \text { humedad } \\
\text { relativa, } 1280 \text { hora/ańo brillo solar }\end{array}$ & 14 \\
\hline Cañones estrechos y profundos & $1000-1400$ & $\begin{array}{l}18-24^{\circ} \mathrm{C}, 1900 \mathrm{~mm} \text { anual, } 80 \% \text { humedad } \\
\text { relativa, } 1825 \text { hora/año brillo solar }\end{array}$ & $\begin{array}{l}18-24^{\circ} \mathrm{C}, 1900 \mathrm{~mm} \text { anual, } 80 \% \text { humedad } \\
\text { relativa, } 1825 \text { hora/año brillo solar }\end{array}$ \\
\hline Cańones estrechos con fondo amplio & $900-1400$ & 3 \\
\hline
\end{tabular}

Tabla 1. Cantidad de sitios (del Cauca Medio) por unidades geomorfológicas con sus características fisiográficas (elaborada por Carlos Eduardo López basado en Lalinde y Toro 2004).

Guarín 2008). La geomorfología de piedemonte del Abanico es diversa; siendo posible identificar unidades de paisaje características de montańa hacia las partes altas y medias de los ríos Otún, Consota, Barbas y Quindío, o, unidades onduladas y planas hacia el suroeste en sectores de los valles del río Verde, La Vieja y Cauca. En el Sector medial, predominan planos inclinados, remanentes de la formación del Abanico que van descendiendo con pendientes suaves; hay presencia de valles profundos que cortan en forma de $V$, entre alturas de aproximadamente 1300 a $1500 \mathrm{msnm}$ (Lalinde y Toro 2004; Guarín 2008) (Tabla 1).

Además del área del abanico, se hicieron recorridos hacia el sector montañoso denudativo ${ }^{8}$ al nororiente de la ciudad de Pereira (municipios de Chinchiná, Manizales y Villa María). Igualmente, hacia el suroriente, se adelantaron visitas por el sector montañoso del Quindío (municipios de Armenia, Calarcá, Salento, Circasia y Quimbaya) (IGAC 2004a; IGAC 2004b; IGAC-CRQGobernación del Quindío-ESAQUIN-EDEQ 2013).

De acuerdo con la síntesis que presenta Cano (2018), los vientos estratosféricos predominantes hicieron que fuera la vertiente al río Cauca la más afectada por la acumulación de depósitos piroclásticos, con impactos de diferente grado de acuerdo a la cercanía a los focos, las pendientes y el tipo de vegetación. El espesor promedio de las cenizas entre Armenia y Pereira es de siete metros, aunque en algunos lugares están completamente erosionadas; en otras partes, se conservaron perfiles de 15 metros de espesor ${ }^{9}$. Las condiciones ambientales del trópico húmedo aunado 


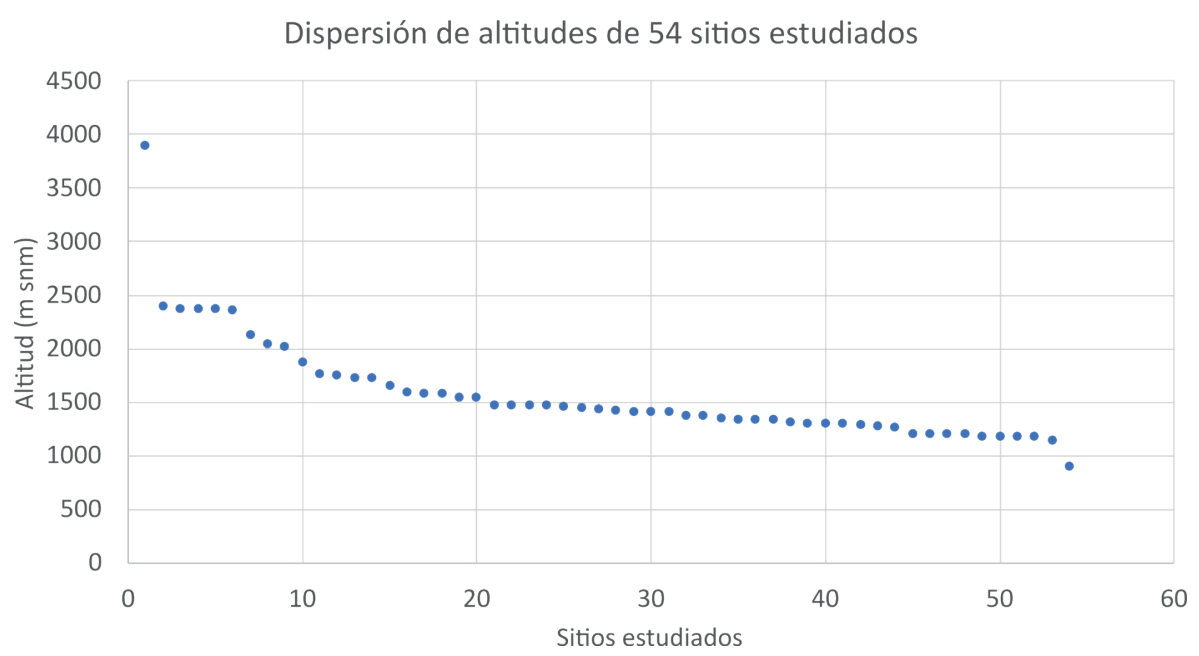

Figura 7. Dispersión de altitudes de mayor a menor altitud de 54 sitios estudiados por el LEHPC. El sitio El Arbolito (sin evidencias arqueológicas) es el más alto, en zona de páramo. Aparece como dato atípico, pero se tomó como referencia estratigráfica por su cercanía a los focos volcánicos. El sitio arqueológico Bosque fue el más bajo en la paleollanura aluvial del Risaralda-Cauca (López, et al., 2016) (figura de Jorge Andrés Vargas, 2019).

a la alta biomasa en superficie han dinamizado su meteorización. La alta precipitación anual (hasta $2500 \mathrm{~mm} /$ año) y las altas temperaturas diarias, fomentan el desarrollo de microorganismos en los suelos, lo que se relaciona con las dinámicas de pedogénesis y bioturbación. La mayoría de estos suelos, —originados por la transformación de cenizas provenientes de los cinco focos volcánicos del Complejo Cerro Bravo-Cerro Machín - se encuentran compuestos de sílice, cuarzo bipiramidal, feldespato, biotita, clino y ortopiroxeno (Camargo et al. 2001).

El sector medio de la Cordillera Central permite correlacionar de manera excepcional la historia del pasado geológico más reciente y las evidencias culturales arqueológicas. Se ha podido demostrar la presencia humana hace al menos 12,000 años en la región, así como los impactos tempranos sobre el paisaje y las sociedades que se desarrollaron en estos entornos (Rojas y Tabares 2000; Montejo y Rodríguez 2001; Aceituno y Loaiza 2007; Jaramillo 2008; Restrepo 2012; Dickau et al. 2015; Herrera et al. 2016; Posada 2017; Aceituno 2019; Cano et al. 2021).

Para correlacionar sitios y obtener proyecciones espacio-temporales y estratigráficas se organizaron en la base Excel los datos de 54 sitios muestreados según la altura en orden descendente sobre el nivel del mar. Se realizó una tabla de intervalos con distribución de frecuencias empírica calculando el rango y estableciendo un número impar de clases (3), se definió la Amplitud (412) (Fig. 7).

La mayoría de los lugares de interés arqueológico muestreados, el 48.14\% (26 sitios) están agrupados en clima templado, entre 1340 y $1840 \mathrm{msnm}$, localizados dentro del abanico fluviovolcánico Pereira-Armenia. Esto no es de extrañar pues se dan allí los mejores contextos ambientales para la habitabilidad, en cuanto a clima y pendientes. El 31.48\% de los sitios estudiados (17) se encuentran en tierra cálida y relativamente más seca, entre los 900 y los $1340 \mathrm{msnm}$, seguidos del 20.38\% en tierras frías y húmedas, donde (11) están situados a más de 1840 msnm (Fig. 8). Los lugares que se resaltaron fueron agrupados según su localización, correspondiendo a sitios dentro del departamento de Caldas (hacia el norte de la ciudad de Pereira), otros sitios al centro en inmediaciones de Pereira (departamento de Risaralda) y otros sitios hacia el sur del abanico fluviovolcánico Pereira-Armenia, en el departamento del Quindío (López et al. 2016; Cano 2018). 


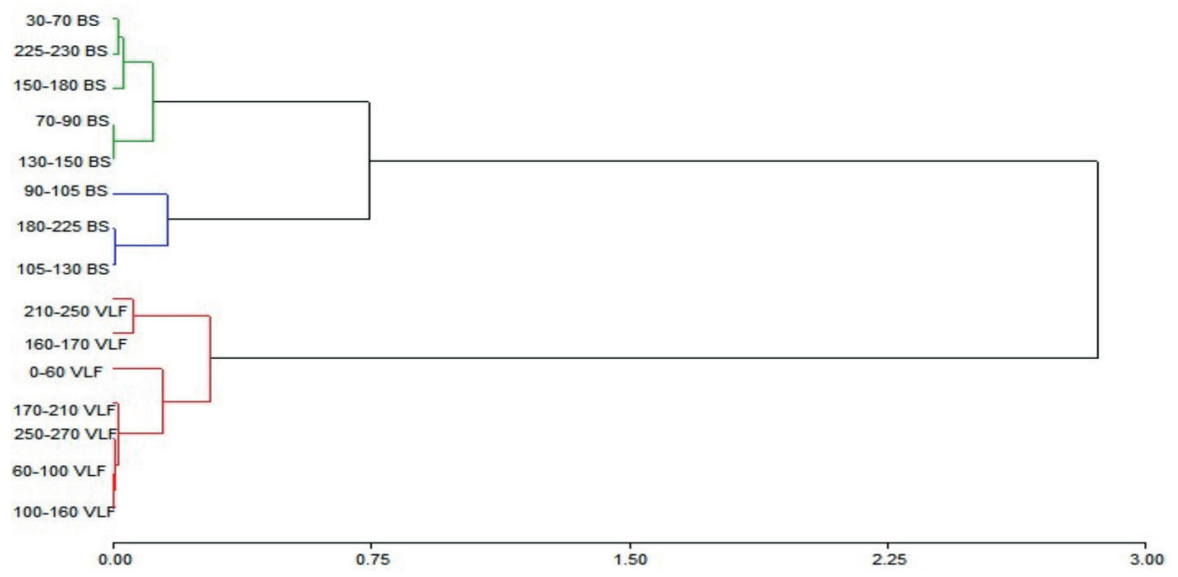

Figura 8. Análisis de conglomerados (Índice Bray - Curtis) para analizar la disimilitud de las variables altitud y promedio de gruesos de horizontes enterrados realizado con InfoStat. Nótese que los grupos más próximos a 0 tienen mayor similitud (figura de Jorge Andrés Vargas, 2020).

$\mathrm{Al}$ noreste de Pereira se destaca un sector donde predomina un relieve denudativo de alta montaña, con topografía diversa, fuertes pendientes y distintas terrazas fluvio-volcánicas con aportes coluviales ${ }^{10}$. Los principales sitios muestreados fueron El Arbolito — como único referente en la zona alta de páramo-- y una secuencia en sitios como Bella Suiza, Valle de la Florida, Aeropuerto del Café, La Guaca y El Bosque, correspondientes al 14.81\% de la totalidad de los lugares analizados. Los sitios Bella Suiza y Valle La Florida tienen secuencias de suelos enterrados y cuentan con evidencias arqueológicas (Cortés et al. 2013; Restrepo 2013). Estos se tomaron como referencia para ser comparados al relacionar los paleosuelos desarrollados (Ab y $\mathrm{Bb}$ ) y sepultados abruptamente por sedimentos de origen volcánico $(\mathrm{Cb})$. Se pudo identificar que estos sitios en alturas mayores a $1800 \mathrm{msnm}$ contienen igual o más del $45 \%$ de su composición mineral gruesa (López et al. 2016; Cano 2018).

Posteriores visitas de campo y correlaciones con la bibliografía ratificaron la posibilidad de determinar reiteradamente en el sector montańoso noroccidental de Pereira, la presencia de al menos dos "estratos guías», los cuales se atribuyen a depósitos de significativas erupciones durante el Holoceno del volcán Cerro Bravo (505’21” N, 75¹7’32” O). Estos depósitos de arenas medias y gruesas entierran suelos orgánicos con evidencias arqueológicas, reflejando impactos directos en distintos puntos de los municipios de Manizales y Villamaría localizados en el flanco occidental de la Cordillera Central a alturas mayores a $2000 \mathrm{msnm}$. Estos depósitos gruesos y los suelos enterrados son menos visibles en la medida que se desciende altitudinalmente (Restrepo 2013; López et al. 2016; Cano 2018; Cano et al. 2021).

Los análisis de laboratorio fueron comparados, sintetizando información de cuatro sitios: Tesorito (Jaramillo, 2008), Bella Suiza (Tabla 2 y Fig. 9) (LEHPC 2017; Álvarez 2020) y La Florida (Cortés et al. 2013; Restrepo 2013); además de Los Arrayanes (Rodríguez 1997), contando con los datos sólo en reportes, pero teniendo en cuenta su importancia por las evidencias arqueológicas estratificadas y los datos cronológicos reportados. En estos sitios los autores habían identificado de manera evidente litoestratos de arenas gruesas sepultando suelos enterrados. Se compararon los porcentajes de los sedimentos de los horizontes húmicos ${ }^{11}$ ( $\mathrm{A}$ y $\mathrm{Ab}$ ) con relación a sedimentos constituyentes de otros horizontes como los B o C, enfatizando los grados de variabilidad. 


\begin{tabular}{|l|c|c|c|c|c|c|c|c|c|c|c|c|}
\hline Horz & $\begin{array}{c}\text { Prof } \\
\mathbf{c m}\end{array}$ & $\begin{array}{c}\% \\
\text { Gruesos }\end{array}$ & Diorita & Granito & Andesita & Pómez & Plagioclasa & Cuarzo & Piroxeno & Anfibol & Epídota & Biotita \\
\hline $\mathrm{Ap} 1 / 2$ & 30 & 54.5 & 33 & 15 & 22 & 4 & 32 & 47 & 20 & 24 & 0 & 3 \\
\hline $\mathrm{AB}$ & 70 & 60 & 42 & 9 & 14 & 0 & 36 & 50 & 12 & 33 & 4 & 0 \\
\hline $\mathrm{B}$ & 90 & 76 & 23 & 0 & 9 & 60 & 56 & 14 & 12 & 26 & 0 & 0 \\
\hline $\mathrm{C}$ & 105 & 94 & 22 & 0 & 0 & 67 & 52 & 6 & 22 & 28 & 0 & 3 \\
\hline $2 \mathrm{ABb}$ & 130 & 60 & 44 & 0 & 2 & 14 & 75 & 14 & 12 & 39 & 0 & 0 \\
\hline $2 \mathrm{Bb}$ & 150 & 53 & 26 & 2 & 0 & 36 & 84 & 13 & 33 & 6 & 0 & 0 \\
\hline $2 \mathrm{Cb}$ & 180 & 95 & 23 & 3 & 2 & 75 & 53 & 6 & 12 & 26 & 0 & 0 \\
\hline $3 \mathrm{ABb}$ & 225 & 56 & 23 & 0 & 0 & 22 & 87 & 19 & 14 & 33 & 0 & 2 \\
\hline
\end{tabular}

Tabla 2. Conteo de minerales por horizontes y profundidades de las muestras por horizontes pedoestratigráficos del corte aledaño a Pozo 123 en Bella Suiza. Datos de \% de Gruesos por LEHPC, otros datos aportados por la Geóloga Daniela Barco (elaborada por LEHPC - Daniela Barco, 2019).

Variación de gruesos por tamiz y profundidad en el sitio Bella Suiza.
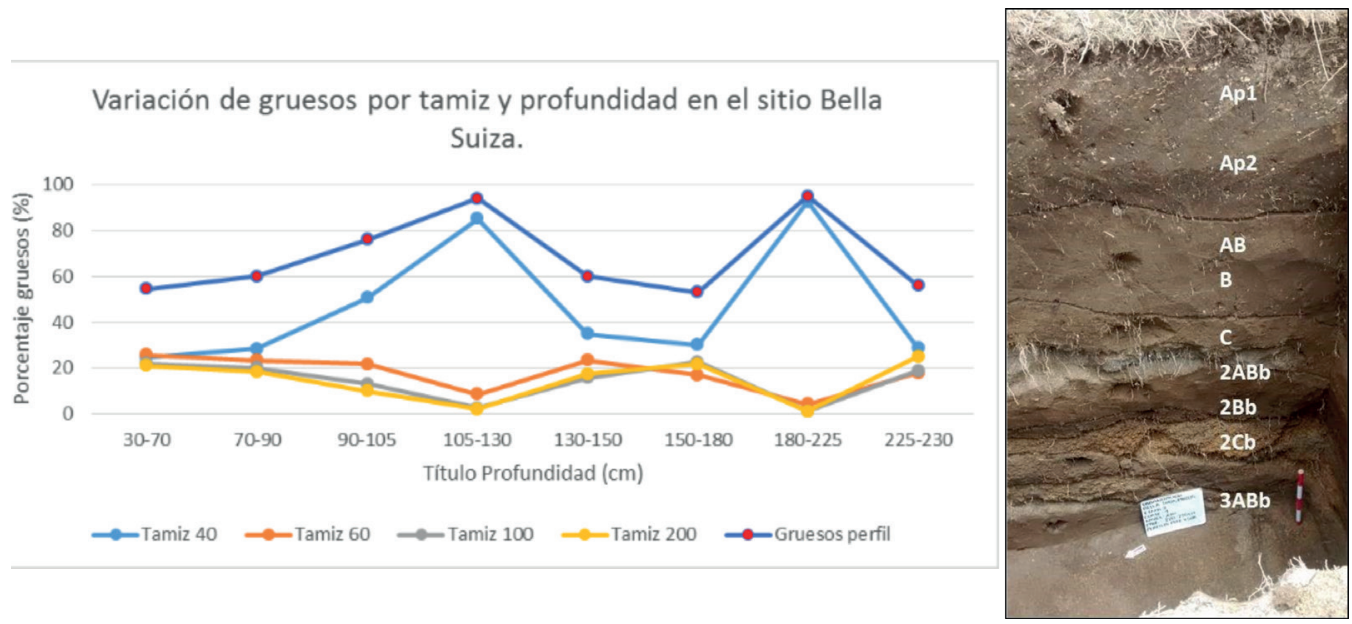

Figura 9. Gráfico y foto de perfil del Sitio Bella Suiza, Manizales. En el gráfico se observa la marcada variación de materiales gruesos por tamices y por profundidad (LEHPC, 2017) (figura de Jorge Andrés Vargas y Carlos Eduardo López, 2017).

Para el sitio Bella Suiza se hicieron análisis de caracterización físico-química de muestras de horizontes de suelos y paleosuelos de una columna y se realizaron análisis de granulometría de ocho niveles de suelos y sedimentos, los cuales fueron diferenciados en campo por texturas y colores $(\mathrm{AB}, 2 \mathrm{ABb}$ y $3 \mathrm{ABb})$. Con el propósito de conocer las características y la fuente de los sedimentos, se adelantó un conteo aleatorio de 100 granos tomados de muestras del centro de los horizontes pedológicos ${ }^{12}$ definidos en campo (Tabla 2). Se analizaron 32 muestras ${ }^{13}$ que indicaron aportes de materiales provenientes tanto del basamento como de los depósitos (LEHPC 2017).

En estos casos las secuencias estratigráficas de los sitios Tesorito, Bella Suiza, La Florida, Villa Clara y Arrayanes muestran una unidad basal asociada a una época eruptiva relacionada con la Transición Pleistoceno-Holoceno (aproximadamente hace 11,000 años AP), indicando 
una relativa calma volcánica. Es en este suelo dónde se han localizado las evidencias precerámicas más tempranas a escala regional de los primeros habitantes de los bosques de montaña (Aceituno y Loaiza 2006; Aceituno y Loaiza 2007; Restrepo 2012; Herrera et al. 2016; Posada 2017; Cano 2018).

En la Tabla 3 presentamos un esquema del tipo de correlaciones que se han podido establecer entre la matriz de suelos, los sedimentos de caída y las evidencias culturales que se han reportado para la zona, basados en nuestros estudios y otros autores (Jaramillo 2008; Cano et al. 2013, 2015, 2021; Restrepo 2013; Dickau et al. 2015; Posada 2017; Cano 2018).

Posada (2017) plantea que el desarrollo de un horizonte húmico (A o Ab) en casi todas las unidades eruptivas, permite inferir un tiempo de estabilidad geomorfológica. Adicionalmente, las fechas radiocarbónicas asociadas, corresponden a periodos con poca magnitud y frecuencia, o sin caída de materiales piroclásticos. Al parecer la estabilidad ambiental inferida de los paleosuelos correspondientes a la Transición Pleistoceno-Holoceno, de los sitios arriba mencionados, cambió sus características, pues, se dio una nueva época de caída permanente de cenizas finas en los primeros momentos y arenas medias y gruesas intercaladas, observables en horizontes $\mathrm{C}$ (sedimentos con pesos porcentuales altos y mayores tamańos de componentes). Estas caídas fueron relativamente continuas hasta los primeros siglos de nuestra era (Posada 2017) ${ }^{14}$. Estos depósitos son visibles en los sectores superiores de todos los perfiles de los sitios estudiados y descritos con detalle particularmente en el sitio Tesorito (Jaramillo 2008), donde se reporta cerámica temprana y tardía correspondiente a sociedades jerárquico-cacicales.

Estos casos, localizados dentro del "gran paisaje de montańa», relativamente cerca a los focos volcánicos, muestran claramente variaciones de la tefraestratigrafía por el tamaño de los sedimentos y los contactos discordantes, lo que permite en estos sectores, contar con una mayor resolución, lo que facilita correlaciones lito-pedo y arqueoestratigráficas ${ }^{15}$. Así, se pudo hacer un ejercicio de promediar y efectuar correlaciones que sirven para mostrar la visibilidad que representan porcentualmente los pesos de los que se definieron como horizontes $\mathrm{Cb}$, o capas de sedimentos compuestos por arenas gruesas. Este ejercicio se repitió también en otros sitios hacia el centro y al sur del sistema volcánico (Fig. 10).

Se pudieron determinar diferencias con el sector central y occidental del Abanico (suroccidente de Pereira) donde predominan más bien secuencias de tefras finas en las que las unidades eruptivas muestran litoestratigrafías con contactos concordantes, aunque se reportan algunas variaciones locales. En las alturas medias en general no siempre son observables a simple vista los paleosuelos, aunque se dan algunas excepciones en el sector norte, donde se ven oscurecimientos marcados de sitios como el 39 de Aerocafé ${ }^{16}$ (Proyecto AEROCAFÉ 2011; Herrera et al. 2016) o como Hacienda Cuba (Ranere y Dickau 2014; Dickau et al. 2015; Cano 2018; Cano 2019), los cuales además están asociados a evidencias arqueológicas. Adicionalmente, hacia el sector sur de Pereira, también se han localizado paleosuelos, estos posiblemente asociados a los depósitos del volcán Cerro Machín (4²9’00” N, 75²3’30” O), los cuales muestran contactos discordantes y niveles gruesos de lapilli (Cano et al. 2013, 2015; López et al. 2016; Cano 2018; Cano et al. 2021).

En los tres amplios sectores muestreados (norte, centro y sur de la ciudad de Pereira) se ha reconocido un patrón relativamente uniforme de composición mineralógica de las tefras ${ }^{17}$, aunque se requiere determinar con mayor detalle si hay diferencias al norte y al sur en las proporciones de algunos minerales y si las distintas capas de las secuencias litoestratigráficas se relacionan con variaciones granulométricas específicas. En general, las subunidades superiores que se extienden hasta la superficie actual son las que poseen mayor desarrollo pedológico y suponen un período de relativa estabilidad en la actividad eruptiva (Aceituno y Loaiza 2007; Posada 2017), por lo menos en los últimos 3600 años (Cano et al. 2013, 2015). Nuevas investigaciones por parte de especialistas permitirán refinar la identificación de eventos específicos que puedan asociarse con edades concretas o eventos de algún volcán particular. Estas últimas afirmaciones se hacen visibles 


\begin{tabular}{|l|c|l|}
\hline Horiz. & Prof. $\mathrm{cm}$ & Correlaciones \\
\hline Ap1/2 & $0-20$ & $\begin{array}{l}\text { Hacia el techo es común el hallazgo de evidencias, modernas, republicanas, coloniales, } \\
\text { cerámica y líticos asociada a grupos agroalfareros tardíos (en sus dos subdivisiones). }\end{array}$ \\
\hline $\mathrm{AB}$ & $20-25$ & $\begin{array}{l}\text { Es común el hallazgo de vestigios de ocupantes agroalfareros tardíos. En otros sitios es más } \\
\text { un horizonte AC que AB. }\end{array}$ \\
\hline $\mathrm{Bw}$ & $25-50$ & $\begin{array}{l}\text { Posibilidad de evidencias agroalfareras tardías a medias. En otros sitios no se alcanza a } \\
\text { formar un verdadero horizonte B. }\end{array}$ \\
\hline $\mathrm{C}$ & $50-70$ & $\begin{array}{l}\text { Capa de arenas gruesas o lapilli. Erupción fuerte que impactó a los habitantes agroalfareros. } \\
\text { Torrenciales en el río Chinchiná y otros. }\end{array}$ \\
\hline $2 \mathrm{Ab}$ & $70-60$ & Suelo enterrado. Ocupación agroalfarera temprana \\
\hline $2 \mathrm{ABb}$ & $60-70$ & Suelo asociado a las ocupaciones agroalfareras tempranas \\
\hline $2 \mathrm{Bb}$ & $80-100$ & Suelo asociado a las ocupaciones agroalfareras tempranas \\
\hline $2 \mathrm{Cb}$ & $100-115$ & Depósito de lapilli producto de una fuerte erupción \\
\hline $3 \mathrm{ABb}$ & $115-125$ & Suelo que se podría asociarse a la ocupación de gentes precerámicas tempranas \\
\hline
\end{tabular}

Tabla 3. Correlaciones estratigráficas y ocupaciones humanas de acuerdo con las secuencias sedimentarias de evidencias y hallazgos en el sitio Bella Suiza, los cuales se corresponden con contextos estratigráficos de los sitios La Florida, Tesorito y Arrayanes (LEHPC 2017) (elaborada por Carlos Eduardo López y Martha Cecilia Cano, 2017.

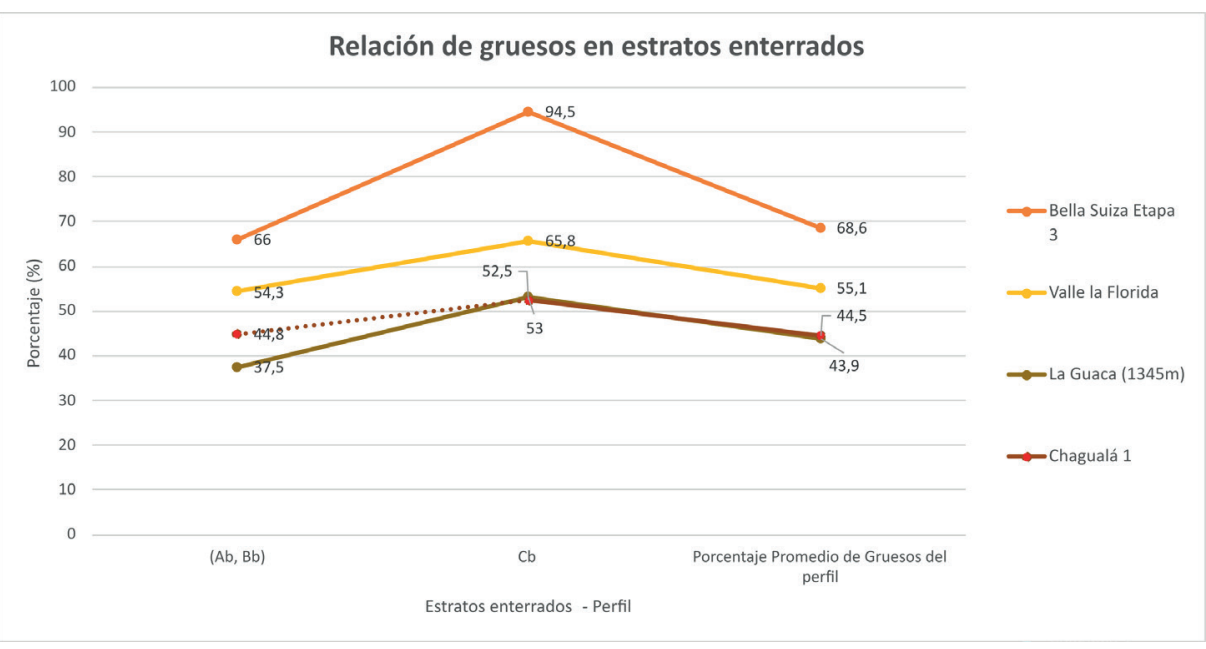

Figura 10. Relación comparativa de los componentes gruesos del suelo en los estratos enterrados bajo depósitos de lapilli o torrenciales ya descritos de Bella Suiza y La Florida. Se presentan a nivel comparativo los datos de los sitios La Guaca y Chagualá a menores alturas (figura de Jorge Andrés Vargas, 2020). 
al comparar los resultados obtenidos en los análisis y generar correlaciones. Por ejemplo, se ve la variación marcada y los picos que se destacan en los sitios a mayor altura en contraste con los datos de los sitios más bajos (Figs. 11 y 12).

\section{Discusión y consideraciones finales}

Los resultados de los análisis de muestras secuenciales de medio centenar de sitios arqueológicos marcan variaciones y tendencias que son significativas para validar el método de análisis sedimentológico propuesto, el cual puede seguir siendo refinado. Por su relativo bajo costo facilita el procesar columnas de varias muestras por sitio y por niveles, permitiendo su comparabilidad en distintos estudios intra e inter sitio. Estos pueden ser fácilmente replicados de acuerdo a nuevas preguntas alrededor del contexto arqueológico o de la formación de los sitios e implicaciones paleoambientales.

Las preguntas desde la arqueología se proyectan en una estratigrafía muy «comprimida» relacionada con el desarrollo de suelos (en escala centimétrica), la cual se contrasta con la escala geológica, vinculada a gruesos depósitos y a la formación macro del paisaje (la cual se suele considerar en escalas de metros). Aunque a nivel superficial de los suelos es posible ver cambios describiendo horizontes pedológicos, no siempre los cambios litoestratigráficos se diferencian a la vista, pues, en muchos casos no se notan variaciones en los componentes minerales y los aspectos texturales. El proceso de análisis sedimentológico de columnas aquí descrito ha permitido diferenciar variaciones estratigráficas, las cuales se traducen en cambios porcentuales en peso y en tamaño de componentes. Se determinó que estas variaciones se hacen más marcadas en los sitios a alturas mayores a $1800 \mathrm{msnm}$, tanto por la cercanía a los focos volcánicos, como por la menor temperatura que no acelera tanto los procesos de meteorización de suelos. Adicionalmente nuestro estudio ha logrado demostrar que a escala centimétrica, son funcionales los niveles de 10 centímetros, como referente para determinar cambios sistemáticos, en ocasiones muy significativos.

Asimismo del mayor interés, fue posible diferenciar cuantitativamente «estratos guía» en las cercanías a los volcanes Cerro Bravo y Nevado del Ruiz, particularmente en el sector de ManizalesVillamaría (nororiente de Pereira). Otra expresión distinta de «estratos guía» se pudo reportar en el sector de Salento-Calarcá-Armenia-Circasia al suroriente de Pereira. Para los alrededores y tierras más bajas al occidente de Pereira no fue siempre evidente la presencia de estratos guías en suelos subsuperficiales. Estos pueden manifestarse como depósitos de arenas gruesas tipo lapilli o por suelos orgánicos enterrados visibles por sus coloraciones oscuras.

Solamente en pocos de los casos estudiados se referenciaron depósitos de sedimentos de tamańos gravillas o superiores. Estos se reportaron en sitios relacionados directa o indirectamente con ambientes fluvio-aluviales. Además, no es común encontrar gravillas u otro tipo de materiales de tamaño mayor que se hubieran depositado de forma natural; así, se corroboró que en la mayoría de ocasiones la presencia guijarros es producto de aportes culturales.

La perspectiva geoarqueológica aporta significativamente al sumar datos interdisciplinarios siguiendo caminos propuestos por los geólogos (Toro y Hermelin 1991; Lalinde y Toro 2004; Tistl 2006) y proyectar inferencias sobre la historia volcánica y la evolución cultural durante el Holoceno. Se requiere dar continuidad y refinar una clasificación de los depósitos en relación con los diversos tipos de ambientes y parámetros estadísticos. Se debe buscar mejorar los procedimientos para conseguir información estandarizada que pueda ser recuperada, almacenada tanto en base de datos como físicamente por distintos arqueólogos, así como difundida a manera de protocolo de seguimiento compartido. Finalmente, este ejercicio resalta la importancia de mantener almacenada una muestra sistemática de estas secuencias en una «sedimentoteca» para la consulta por otros investigadores que puedan dar continuidad futura a estudios especializados en distintos campos de estudios de suelos y sedimentos. 


\section{Relación porcentual de sedimentos gruesos por sitios arqueológicos del sector Norte, Centro y Sur}

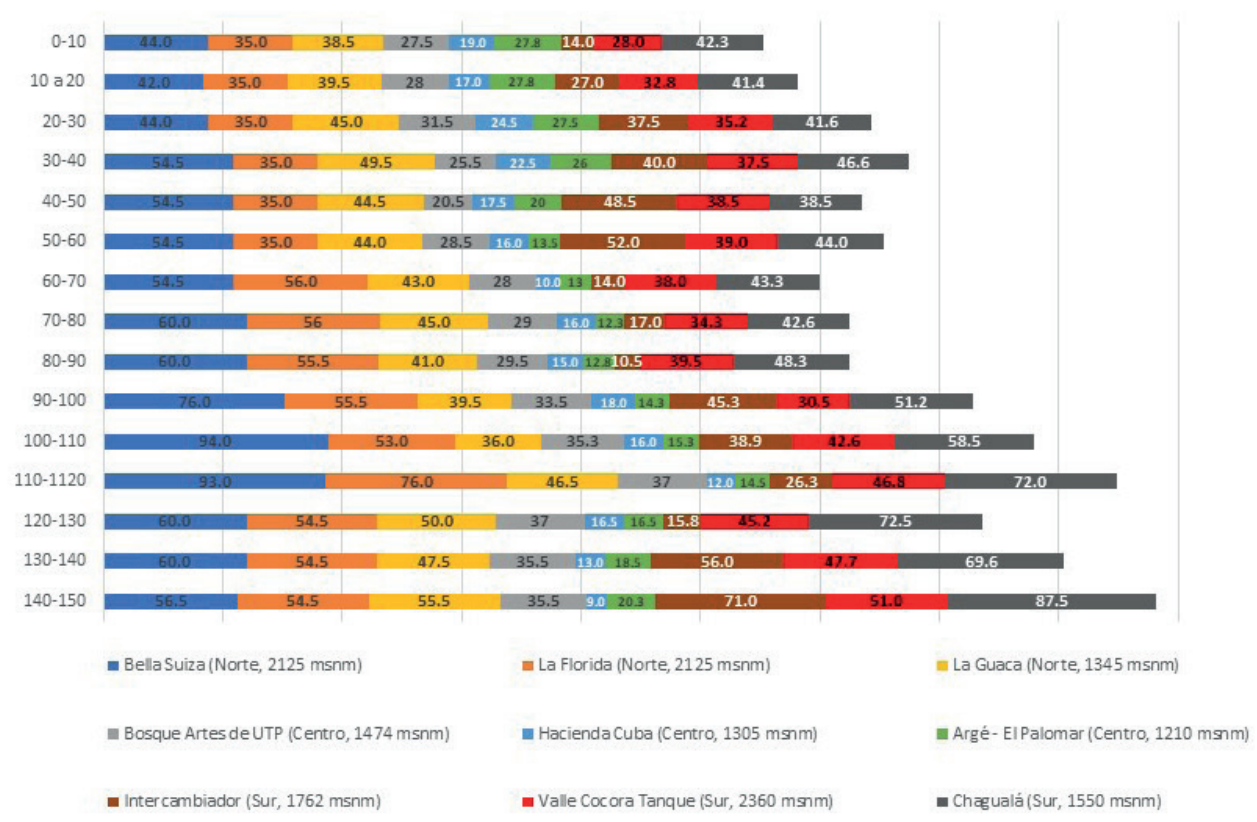

Figura 11. Gráfico que presenta relación entre promedios de todos los niveles excavados de los componentes gruesos (figura de Jorge Andrés Vargas, 2020).

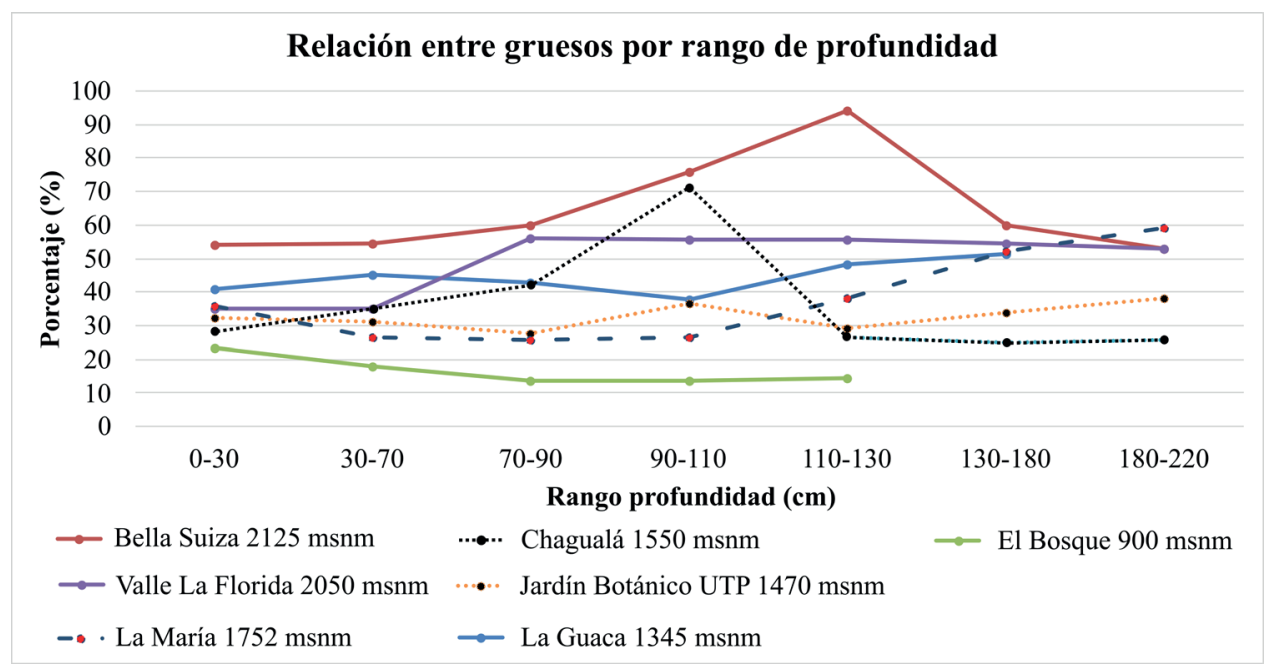

Figura 12. Gráfico relación entre los sitios La María, El Bosque, Bella Suiza, Chagualá, Jardín Botánico UTP, Valle La Florida y La Guaca (figura de Jorge Andrés Vargas, 2020). 


\section{Agradecimientos}

Nuestro reconocimiento póstumo al geólogo Michael Tistl (q.e.p.d.) por todos sus aportes y por infundirnos tanto entusiasmo para el estudio de los sedimentos y contextos volcánicos. Al pedólogo Pedro José Botero por sus enseñanzas sobre suelos y al ingeniero geólogo Ricardo Méndez del Servicio Geológico Colombiano por compartir su conocimiento sobre los ambientes volcánicos. Agradecemos por las invitaciones a conocer excavaciones y contar con los datos obtenidos a los arqueólogos Carlos Restrepo, Ana L. Álvarez, Francisco Aldana, Carlos A. Orjuela y Cristian Marulanda. Nuestro agradecimiento por sus aportes teóricos y en campo a los profesores Cristian Favier-Dubois (UNICEN-Argentina) y Julio Cesar Rubin de Rubin (PUC Goias, Brasil). A los colegas investigadores y estudiantes que han participado en los procesos de laboratorio (LEHPC): Luz Marina Mora, Carmen Elisa Henao, Ángela Barco, José Nizama, Daniela Barco, Juan David Arango, Fernando Viáfara, Daniel Osorio, Carlos Mauricio Mena. Inicialmente el proyecto fue cofinanciado por Colciencias y la UTP; como uno de sus productos se obtuvo la tesis doctoral de Cano (2018). A la Vicerrrectoría de Responsabilidad Social y Bienestar Universitario de la UTP por el apoyo con monitorias sociales.

\section{Notas}

${ }^{1}$ Dando continuidad a las propuestas del geólogo Michael Tistl, y a partir de la cofinanciación entre un proyecto UTP-Colciencias (López et al. 2016) el cual tuvo como uno de sus productos una tesis doctoral (Cano 2018).

${ }^{2}$ Con excepción de la Universidad de Caldas que ha incluido en su programa de antropología cursos en geoarqueología y otros afines.

${ }^{3}$ Previamente hicimos ensayos con algunos métodos para la dispersión de los elementos que enmascaran los minerales, sin lograr resultados exitosos. A partir de pruebas de ensayo y error, llegamos a la conclusión que nuestra propuesta funcionaba adecuadamente para las necesidades de registrar visibilidad y variabilidad.

4 Según cinco clases granulométricas, en tamices clasificados por el Departamento de Estandarización de Estados Unidos (U.S. STD. Sieve) según el número y abertura de malla y adoptados por el LEHPC como: tamiz $40(0.420 \mathrm{~mm})$, tamiz $60(0.25 \mathrm{~mm})$, tamiz $100(0.149$ $\mathrm{mm})$, tamiz $200(0.074 \mathrm{~mm})$ y fondo $(0.044 \mathrm{~mm})$.

${ }^{5}$ Murcia et al. (2008) retoman la escala de Udden y sus modificaciones, que diferencia entre tamańos: arcilla, limo, arena, guijo, guijarro y bloque. Adicionalmente recuerdan que Smith propone ceniza fina, ceniza gruesa, lapilli, bloques, bombas.

${ }^{6}$ Aquellos minerales cristalinos de tamaño considerable, con respecto a los demás componentes. Su estructura se debe a la lenta solidificación y cristalización del magma.

${ }^{7}$ Se destacan rocas cretáceas resumidas como Grupo Diabásico (basaltos o diabasas y meta sedimentos pertenecientes a corteza oceánica), así como partes de arcos de islas. La base del abanico está conformada por la presencia de materiales transportados por flujos de lodo con espesores de varios cientos de metros, flujos piroclásticos (ignimbritas), cenizas volcánicas antiguas fuertemente meteorizadas, y cenizas volcánicas jóvenes (Toro y Hermelin 1991; Guarín et al. 2004; Lalinde y Toro 2004; Tistl 2006; Guarín 2008).

${ }^{8}$ Procesos de erosión, fragmentación y movimiento de suelo y/o roca. La denudación se refiere a la pérdida de material por erosión y meteorización de rocas y minerales.

9 Thouret y van der Hammen (1981) plantearon que desde hace $c .40,000$ años ha dominado un volcanismo explosivo, representado en caídas de cenizas en el piedemonte. Las cenizas antiguas son de color café oscuro, compactas, con estratos ricos en materia orgánica y en la parte superior son turbas (Tistl 2006). Discordantemente en los últimos 20,000 ańos, se depositó una nueva 
secuencia de cenizas de colores grises-amarillas-rojizas, con estratificación, estructura y textura menos compactadas (Toro y Hermelin 1991; Lalinde y Toro 2004).

${ }^{10}$ Movimiento de erosión y desprendimiento vertical de masas de suelo y/o roca en zonas de altas pendientes.

${ }^{11}$ Horizonte orgánico en el que se está llevando a cabo la acumulación superficial de la materia orgánica que cae al suelo. La materia orgánica sigue un ciclo de descomposición, recombinación, polimerización y condensación que acaba en la formación de sustancias húmicas, propias y exclusivas del suelo. En esa transformación predominan los procesos oxidativos que culminan en su mineralización.

${ }^{12}$ Horizontes clasificados en su medio natural (O, A, B y C). Se diferencia entre la nomenclatura pedológica y edafológica.

${ }^{13}$ Productos recuperados en los tamices N. $40,60,100$ y 200 de cada uno de los ocho horizontes pedológicos. Según la composición predominante se realizó un diagrama por cada intervalo. Las secciones estudiadas fueron: Unidad Superior que corresponde a los primeros cuatro horizontes pedológicos del perfil, Unidad Inferior que son los últimos cuatro horizontes del perfil.

${ }^{14}$ Adicionalmente, la tesis doctoral de Posada (2017) hace aportes contextuales de gran importancia, señalando que las capas tefraestratigráficas observadas y correlacionadas en tres sitios cercanos (Chinchiná, Manizales y Neira) según sus características sedimentarias y cronológicas, muestran una secuencia general de seis unidades eruptivas sucedidas durante el Holoceno, las cuales han tenido diferentes consecuencias a escala regional, teniendo en cuenta la recurrencia y la explosividad, así como otros factores relacionados con el relieve y los vientos.

${ }^{15}$ Por ejemplo, el estudio sedimentológico del sitio El Arbolito, en el sector alto del páramo, indicó como relación porcentual de pesos, un dato de $81.1 \%$ de sedimentos gruesos, en depósitos que pueden atribuirse a productos caídos en las últimas erupciones con mayor potencia, además muy poco meteorizados. Este sitio no mostró evidencias arqueológicas, pero sirvió de referente lito y pedo estratigráfico (Cano 2018).

${ }^{16}$ Proyecto de Arqueología Preventiva del Aeropuerto del Café Palestina (AEROCAFÉ) (Caldas).

${ }^{17}$ Fragmento sólido de origen volcánico (piroclástico) que tiene un tamaño entre lapilli (2-64 $\mathrm{mm})$ y ceniza $(<2 \mathrm{~mm})$.

\section{Referencias}

Aceituno, F. (2019). Entre el río y la montaña. Nuevos datos para el poblamiento temprano del Cauca Medio colombiano, Universidad de Antioquia, Medellín.

Aceituno, F. y N. Loaiza (2006). Una aproximación ecológica al poblamiento del Cauca Medio entre el Pleistoceno Final y el Holoceno Medio, en: C. López, M. Cano y D. Rodríguez (eds.), Cambios Ambientales en Perspectiva Histórica. Ecología Histórica y Cultura Ambiental, vol. 2, 42-55, Universidad Tecnológica de Pereira/Sociedad Colombiana de Arqueología, Pereira.

Aceituno, F. y N. Loaiza (2007). Domesticación del bosque en el Cauca Medio colombiano entre el Pleistoceno Finaly el Holoceno Medio, Archaeopress, BAR International Series 1654, Oxford.

Álvarez, A. (2020). Programa de arqueología preventiva. Implementación parcial del plan de manejo arqueológico (2,7 ha para prospección y 30983,53 $\mathrm{m}^{2}$ para monitoreo), Proyecto de Vivienda Bella Suiza, Manizales, Caldas, informe final sin publicar, Constructora Berlín S.A.S., Manizales.

Botero, P. (2001). Relaciones entre las ciencias de la tierra y la arqueología, en: G. Morcote (ed,), Simposio pueblos y ambientes:una mirada al pasado precolombino, 7-45, Academia Colombiana de Ciencias Exactas, Físicas y Naturales/Universidad de los Andes, Bogotá.

Camargo, J., J. Ríos y M. Valencia (2001). Estimación de áreas bajo andisoles y sus características físicas, químicas y mineralógicas en Risaralda y Quindío, en: Suelos del Eje Cafetero, 125-142, Proyecto UTP-GTZ, Pereira. 
Cano, M. (2018). Cambios ambientales del Pleistoceno Final al Holoceno Medio e impactos humanos en el paisaje: estudio geoarqueológico en el abanico fluvio-volcánico Pereira-Armenia, Colombia, tesis de doctorado, Doctorado en Arqueología, Universidad Nacional del Centro de la Provincia de Buenos Aires, Olavarría, Argentina.

Cano, M. (2019). Paisajes, Suelos y actividades humanas precerámicas en el abanico fluvio-volcánico PereiraArmenia, región del Cauca Medio, Colombia, International Journal of South American Archaeology 15, 62-77.

Cano, M., G. Cortés, C. López y R. Méndez (2015). Relación geoarqueológica en depósitos de caída piroclástica del volcán Cerro Machín en el sector de Chagualá, Calarcá (Quindío - Colombia), en: J. Rubin, C. Favier y R. da Silva (eds.), Geoarqueologia na América do Sul, 221-264, Pontifícia Universidade Católica de Goiás, Goiania.

Cano, M., C. López y R. Méndez (2013). Geoarqueología en ambientes volcánicos: impactos ambientales y evidencias culturales en el Cauca Medio (Centro Occidente de Colombia), en: J. Rubin y R. da Silva (eds.), Geoarqueologia, 227-268, Pontifícia Universidade Católica de Goiás, Goiâna.

Cano, M., C. López y R. Méndez (2021). Archaeological evidences on early peopling in the fluvio-volcanic Pereira-Armenia fan (Colombia): Volcanic activity influence on cultural adaptation and depopulation events, Quaternary International 578, 131-198.

Cortés, G., J. Ceballos, L. Valencia y C. Restrepo (2013). Geoarqueología del sector de La Florida en el municipio de Villa Maria, Caldas: implicaciones en la gestión del riesgo volcánico para la amenaza por caídas piroclásticas del Volcán Cerro Bravo, informe final sin publicar, Servicio Geológico Colombiano, Manizales.

Dickau, R., F. Aceituno, N. Loaiza, C. López, M. Cano, L. Herrera, C. Restrepo y A. Ranere (2015). Radiocarbon chronology of terminal Pleistocene to middle Holocene human occupation in the Middle Cauca Valley, Colombia. Quaternary International 363, 43-54.

Favier-Dubois, C. (2010). Geoarqueología: explorando propiedades espaciales y temporales del registro arqueológico, en: R. Barberena, K. Borrazzo y L. Borrero (eds.), Perspectivas actuales en arqueología argentina, 36-54, CONICET-IMHICIHU, Buenos Aires.

Guarín, F. (2008). Etude du fan fluvio-volcanique du Quindio (Région d'Armenia Colombie). Université de Geneve, these de grade de Docteur, Faculté des Sciences, Département de Géologie et Paléontologie, Geneve.

Guarín, F., G. Gorin y A. Espinosa (2004). A Pleistocene stacked succession of volcaniclastic massflows in central Colombia: the Quindio-Risaralda fan, Acta vulcanologica: Journal of the National Volcanic Group of Italy 16, 109-124.

Herrera, L., M. Moreno y O. Peña (2016). Datos de un estudio sobre la ocupación humana en la Cordillera Central de Colombia: el Proyecto Arqueológico AEROCAFÉ (Palestina, Caldas), Boletín Museo del Oro, 56, 103-173.

Instituto Geográfico Agustín Codazzi (IGAC) (2004a). Estudio general de suelos y zonificación de tierras. Informe técnico. Departamento de Risaralda, Bogotá.

Instituto Geográfico Agustín Codazzi (IGAC) (2004b). Estudio general de suelos. Departamento de Caldas, Bogotá.

Instituto Geográfico Agustín Codazzi (IGAC)- Corporación Autónoma del Quindío (CRQ)-Gobernación del Quindío-Empresa Sanitaria del Quindío (ESAQUIN) - Empresa de Energía del Quindío (EDEQ) (2013). Estudio Semidetallado de Suelos del Quindio. s.l. Armenia.

Jaramillo, L. (2008). Sociedades prehispánicas en el territorio "Quimbaya»: unidades domésticas, áreas de actividad y el Complejo Tesorito (1 ${ }^{\text {a }}$ Ed), Fundación de Investigaciones Arqueológicas Nacionales, Banco de la República, Bogotá.

Lalinde, C. y G. Toro (2004). Aspectos geomorfológicos en las cuencas de los ríos Otún y Consotá, en: C. López y M. Cano (eds.), Cambios ambientales en perspectiva histórica. Ecorregión Eje Cafetero, vol. 1, 26-40, Universidad Tecnológica de Pereira/Proyecto UTP-GTZ, Pereira.

Laboratorio de Ecología Histórica y Patrimonio Cultural (LEHPC) (2016). Informe sobre análisis sedimentológicos y granulométricos. sitios La Guaca y El Edén, LEHPC-UTP, Pereira.

Laboratorio de Ecología Histórica y Patrimonio Cultural (LEHPC) (2017). Informe sobre análisis sedimentológicos y granulométricos, urbanización Bella Suiza, Manizales (Caldas), LEHPC-UTP, Pereira.

López, C., C. Henao, M. Dossman, H. Vásquez, J. Arango, L. Mora y D. Cárdenas (2016). Impactos de las erupciones volcánicas durante los últimos 12.000 años en la Región Cauca Medio, Centro Occidente de Colombia: aportes de la geoarqueología y gestión del riesgo al conocimiento de interacciones milenarias naturaleza-cultura, informe final sin publicar, COLCIENCIAS/UTP, Bogotá.

Méndez, R. (2004). Metodología para el análisis sedimentológico de muestras volcánicas, Instituto Colombiano de Geología y Minería (INGEOMINAS), Manizales. 
Montejo, F. y E. Rodríguez (2001). Antiguos pobladores y labranzas en el valle medio del río Otún, Risaralda Boletín de Arqueología 16, 37-115, Fundación de Investigaciones Arqueológicas Nacionales. Banco de la República, Bogotá.

Murcia, H., G. Cortés y B. Hurtado (2008). Métodos e integración de análisis granulométrico para depósitos volcaniclásticos, Boletín Geológico 42(1-2), 129-139.

Posada, W. (2017). Arqueología en territorios de incandescencia: Una aproximación geográfica a los procesos de cambio social y ambiental bajo condiciones de volcanismo activo. Cordillera Central de Colombia, tesis de doctorado, Universidad Nacional de Colombia, Departamento de Geografía, Bogotá.

Proyecto Aeropuerto del Café (AEROCAFÉ) (2011). La Historia muy antigua del municipio de Palestina (Caldas). Proyecto de rescate y monitoreo arqueológico del Aeropuerto del Café, Centro de Museos Universidad de Caldas/Asociación Aeropuerto del Café, Manizales.

Ranere, A. y R. Dickau (2014). The role of the Middle Cauca River Valley, Colombia, in the early domestication and dispersal of New World crops: Final report, National Science Foundation, Washington, D.C.

Rapp, G. y C. Hill (1998). Geoarchaeology. The earth-science approach to archaeological interpretation, Yale University Press, New Haven.

Restrepo, C. (2012). Monitoreo arqueológico fase II. (km $11+400 \mathrm{al} \mathrm{km} 13+100)$ sitios 57, 56, 52 y 55 al Proyecto de Desarrollo Vial Armenia Pereira Manizales, Autopista del Café, informe final sin publicar, Instituto Nacional de Vías (INVIAS)/Autopistas de Café S.A., Pereira.

Restrepo, C. (2013). Componente arqueológico Condominio Campestre «Valle de la Florida», etapas I y II, informe final sin publicar, Villamaría, Caldas, Constructora Berlín S.A.S., Villamaría.

Rodríguez, C. (1997). Rescate arqueológico sitios Los Arrayanes Pk 91+150 Villamaría-Caldas y El Pomo Pk 7+200 ramal a Manzanares, Fresno-Tolima, informe final sin publicar, ECOPETROL, Bogotá.

Rojas, S. y D. Tabares (2000). Aportes para una historia en construcción. Arqueología de rescate en la doble calzada Manizales-Pereira-Armenia, informe final sin publicar, INVÍAS/CISAN, Bogotá.

Thouret, J., y van der Hammen, T. (1981). Una secuencia holocénica y tardiglacial en la Cordillera Central de Colombia. CIAF 6(1-3), 609-634.

Tistl, M. (2006). La formación geológica del paisaje en el piedemonte del Eje Cafetero Colombiano, en: C. López, M. Cano y D. Rodríguez (eds.), Cambios ambientales en perspectiva histórica. ecología histórica y cultura ambiental, vol. 2, 79-92, Universidad Tecnológica de Pereira/Sociedad Colombiana de Arqueología, Pereira.

Toro, G. y M. Hermelin (1991). Proyecto Tefraestratigrafía Colombiana, II etapa. Tefraestratigrafía del departamento de Risaralda, informe final, Universidad Eafit, Medellín.

Waters, M. (1992). Principles of geoarchaeology. A North American perspective, The University of Arizona Press, Tucson. 
